\title{
Prokinetic Effect of Duodenal Extract on Ovine Gallbladders
}

\author{
M. Al-Hussaini M.A. Oriowo E. Philip O. Thulesius \\ Department of Pharmacology and Toxicology, Faculty of Medicine, Kuwait University, \\ Kuwait
}

\section{Key Words}

Gallbladder motility · Interdigestive migration contractions - Erythromycin . Duodenum · Motilin

\begin{abstract}
Objective: It is known that the macrolide antibiotic erythromycin stimulates gastrointestinal and gallbladder motility by an as yet unidentified mechanism. It was the objective of this study to investigate the mechanism of the gallbladder motility-stimulating effect of erythromycin. Methods: In our experiments we used strips of sheep gallbladders measuring isometric tension in organ baths. Since erythromycin itself did not induce contraction we examined the prokinetic effects of sheep duodenal extract, incubated with (DEX) or without (blank) erythromycin $\left(10^{-5}\right.$ M). Results: Both DEX and blank elicited gallbladder contraction associated with heat-stable, water-soluble but not with lipid-soluble
\end{abstract}

\begin{tabular}{ll}
\hline KARGER & ( ) 2000 S. Karger AG, Basel \\
1011-7571/00/0091-0074\$17.50/0 \\
$\begin{array}{l}\text { Fax +4161306 1234 } \\
\begin{array}{l}\text { E-Mail karger@karger.ch } \\
\text { www.karger.com }\end{array}\end{array}$ & $\begin{array}{l}\text { Accessible online at: } \\
\text { www.karger.com/journals/mpp }\end{array}$
\end{tabular}

duodenal prokinetic factor. The factor is unrelated to motilin or cholecystokinin and is only partially $(<20 \%)$ blocked by atropine $\left(10^{-6} \mathrm{M}\right)$ and not affected by the pretreatment with dexamethasone or somatostatin. Conclusion: It was concluded that erythromycin indirectly stimulates contraction of ovine gallbladders through the endogenous release of a duodenal prokinetic factor.

$$
\text { Copyright }(\text { C } 2000 \text { S. Karger AG, Basel }
$$

\section{Introduction}

The physiological control of gallbladder motility by neurogenic and humoral mechanisms is of clinical relevance since stasis of bile is an important risk factor in the pathogenesis of cholesterol gallstones [1]. Gallbladder motor function is controlled by extrinsic (vagus, splanchnicus) and intrinsic nerves (projections from the enteric neurones) and humoral factors. The principal mechanism

Professor Olav Thulesius

Department of Clinical Physiology

University Hospital

S-58185 Linköping (Sweden) 
for the stimulation of gallbladder emptying has long been considered to be the release of cholecystokinin (CCK) from the duodenal mucosa, stimulated by the presence of food. Other hormones inducing gallbladder smooth muscle contraction are reported to be gastrin and motilin [2], but in the case of motilin, activation of gallbladder contraction seems to be mediated by a neurogenic cholinergic reflex secondary to the initiation of migrating motor complexes of the gut by this peptide [3].

The macrolide antibiotic erythromycin enhances intestinal motility in a variety of species, but the extact mechanism of action has not been satisfactorily explained. Some studies suggest that erythromycin has a direct contractile effect on intestinal smooth muscle cells mediated by motilin receptors while others presented evidence for an indirect prokinetic action through the release of motilin from the gastrointestinal wall (stomach, duodenum) [4]. Furthermore, there is evidence that erythromycin at lower doses exerts a prokinetic effect through stimulation of enteric cholinergic nerves [5]. It was the objective of this study to elucidate the mechanism of the prokinetic activity of erythromycin on the gallbladder and to identify the active principle(s).

\section{Materials and Methods}

\section{Tissue Preparation}

Gallbladders and duodenums from Australian Merino sheep of either sex were obtained fresh from the local slaughterhouse and quickly transported, in Krebs' solution on ice, to the laboratory. After carefully removing any adhering connective tissue, transverse strips $(20 \times 2 \mathrm{~mm})$ were prepared from the funds of the gallbladder. Other specimens obtained for testing were: rat aorta (ring), rat stomach (strip), guinea pig ileum (strip) and sheep trachea (strip). Each strip was tied at both ends and suspended in a 40-ml organ bath containing Krebs' solution $(\mathrm{NaCl}, 119 ; \mathrm{KCl}, 4.7$;

Duodenal Prokinetic Factor
$\mathrm{NaHCO}_{3}, 25 ; \mathrm{KH}_{2} \mathrm{PO}_{4}, 1.2 ; \mathrm{MgSO}_{4}, 1.2 ; \mathrm{CaCl}_{2}, 2.5$ and glucose, $11 \mathrm{mM} ; \mathrm{pH}=7.4$ at $37^{\circ} \mathrm{C}$ ). The solution was continuously gassed with a $5 \% \mathrm{CO}_{2} / 95 \% \mathrm{O}_{2}$ mixture. From the washed sheep duodenum 20-mm ring specimens were cut and of these $4 \mathrm{~g}$ of tissue were incubated in test tubes containing $4 \mathrm{ml}$ of Krebs' solution $(1 \mathrm{~g}$ tissue $/ \mathrm{ml})$ and kept at room temperature. After $1 \mathrm{~h}$ the supernatant was removed and used as 'blank'. To other specimens incubated with Krebs' solution, erythromycin $\left(10^{-5} \mathrm{M}\right)$ was added to obtain a 'duodenalerythromycin extract' (DEX). DEX was also obtained in the presence of atropine, the $5-\mathrm{HT}_{3}$-receptor antagonist tropisetron, dexamethasone and somatostatin (all $\left.10^{-6} \mathrm{M}\right)$. Additionally, for a qualitative screening of contractile activity we also tested gallbladder strips from rabbits, guinea pigs and pigs, stomach strips (rats), guinea-pig ileum and rat tracheal rings.

\section{Tension Recording Protocol}

The preparations were allowed to equilibrate under a resting tension of $2.0 \mathrm{~g}$ (sheep), $1.0 \mathrm{~g}$ (guinea pig, rabbit) for up to 120 min during which time the bath fluid was changed at regular intervals. Isometric tension was recorded, through Dynamometer UF1 transducers (Piden Controls Ltd.), on two-channel Lectromed Multitrace recorders.

The first part of the experiments included testing of an aliquot of the blank ( $1 \mathrm{ml}$ added to the 40-ml organ bath). After washing, a single dose $(1 \mathrm{ml})$ of the $10^{-5} \mathrm{M}$ DEX solution was added to the organ bath and the contractile response recorded and allowed to plateau. At the end of the DEX-induced contraction, atropine $\left(10^{-6} M\right)$ was added to the change in tension recorded. Tension was also recorded with boiled blank and DEX solutions $\left(5 \mathrm{~min}\right.$ at $\left.100^{\circ} \mathrm{C}\right)$. Furthermore, contractility of the gallbladder was also tested with carbachol, histamine, erythromycin, motilin (all $10^{-6} M$ ) and CCK $\left(10^{-12} M\right)$. Motility data were only accepted from preparations that initially responded adequately to a test dose of carbachol $\left(10^{-5} \mathrm{M}\right)$.

\section{Extraction}

An aliquot $(1.5 \mathrm{ml})$ of the aqueous extract of duodenal slices with or without erythromycin (DEX) was extracted with $1 \mathrm{ml}$ diethyl ether, chloroform or ethyl acetate (HPLC grades). The dried extracts were reconstituted in saline and added to the organ bath and tested for contractile activity. Heating of the samples for $5 \mathrm{~min}$ was performed in a water bath.

\section{Drugs}

The following compounds were used in the study: carbachol hydrochloride, chloropheniramine, atropine 
Fig. 1. Original trace of sheep gallbladder-strip contraction in response to the addition of duodenal extract (blank, upper trace) and duodenal extract pretreated with erythromycin (DEX, lower trace).
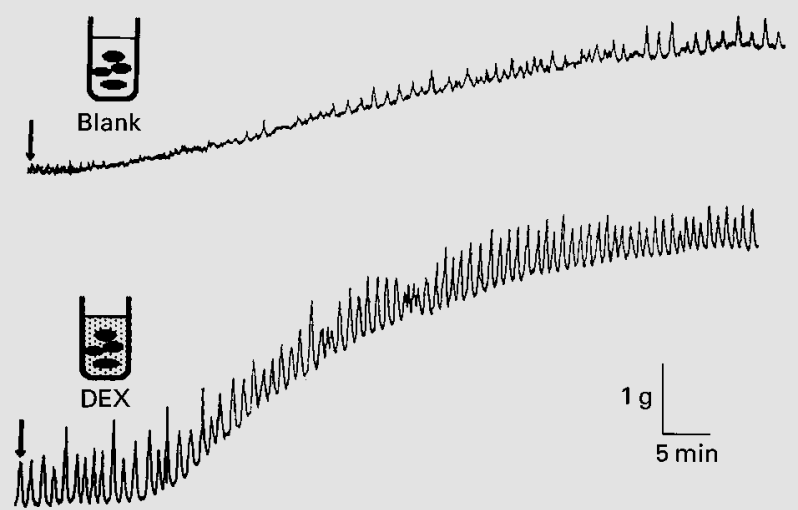

Table 1. Contractile response of tissues from various species to sheep duodenal extract

\begin{tabular}{llllll}
\hline & Sheep & Rat & Rabbit & \multicolumn{2}{c}{ Guinea pig Pig } \\
\hline Gallbladder & + & NT & - & + & + \\
Stomach & + & + & NT & NT & NT
\end{tabular}

$+=$ Contraction $;-=$ no response NT = not tested.

sulphate, histamine, indomethacin, porcine motilin, [Leu ${ }^{15}$-gastrin I, dexamethasone, nordihydroguaiaretic acid, all from Sigma Chemicals (St. Louis, Mo., USA). Erythromycin lactobionate from Abbot Laboratories (North Chicago, Ill., USA), somatostatin acetate from UCB Pharma (Braine-L'Alleud, Belgium), CCK (CCK-8 sulphated), the selective CCK receptor antagonist lorglumide sodium and the 5- $\mathrm{HT}_{3}$-receptor antagonist tropisetron from Research Biochemicals (Natick, Mass., USA).

\section{Data Analysis}

Results are presented as mean \pm SE of ' $n$ ' experiments. Differences between mean values were tested for statistical significance using Student's t test and the difference was assumed to be significant when $\mathrm{p}<$ 0.05 .

\section{Results}

Sheep gallbladder strips when mounted in the organ bath and subjected to a pretension of $2 \mathrm{~g}$ exhibited a considerable degree of spontaneous tone over a period of 1-2 h. After stabilization subsequent administration of carbachol invariably induced further contraction which was reversible after washing with Krebs' solution.

\section{Prokinetic Activity}

Neither erythromycin nor motilin $\left(10^{-6}\right.$ $10^{-5} \mathrm{M}$ ) exerted an effect on smooth muscle tone of any of the gallbladders tested. However, the blank (supernatant of duodenal specimens incubated in Krebs' solution) and the erythromycin extract (DEX) clearly induces dose-dependent contractions in sheep, a finding which implicates the presence of a duodenal prokinetic factor (fig. 1). The onset of contractile response to the duodenal extract varied from 1 to $2 \mathrm{~min}$ and usually peaked in about 20-30 min. The level of contraction was maintained as long as the tissue was in 
contact with the preparation. The extract also contracted guinea-pig and pig gallbladder strips (table 1). No contractions were elicited with the blank or DEX in sheep tracheal strip, rat aortic or the guinea-pig ileum. This would possibly have indicated that the extract was selective for the gallbladder strips but for the fact that the rat stomach strip was also contracted by the duodenal extract.

Interestingly, though erythromycin was by itself devoid of any contractile activity, the erythromycin-pretreated extract elicited slightly but significantly higher contractions, compared with the blank (fig. 2).

\section{Duodenal Prokinetic Factor}

The release of a prokinetic factor from the duodenum was not dependent on a cholinergic muscarinic or serotonergic process since pretreatment of the duodenal specimens with atropine or tropisetron $10^{-5} \mathrm{M}$ did not alter the response. In order to exclude eicosanoidinduced contraction by prostanoids and leukotrienes in the tissue extract, we pretreated the duodenal specimens with $3 \times 10^{-6} \mathrm{M}$ indomethacin or dexamethasone $\left(10^{-5} M\right)$ during the 1-hour incubation period with erythromycin or directly upon harvest of ovine specimens in the Krebs' solution of the transport container from the slaughterhouse to the laboratory. This treatment did not inhibit or reduce the prokinetic effect on the gallbladder strips, neither did pretreatment with the histamine-1 antagonist chlorpheniramine or somatostatin affect gallbladder contraction elicited by the blank or DEX solutions. Addition of the 5-HT $-\mathrm{HT}_{3}$-receptor blocker tropisetron or the specific CCK receptor blocker lorglumide to the organ bath did not reduce gallbladder contractions while atropine produced a small reduction $(<20 \%)$ in response. Furthermore, heat treatment (boiling in a water bath) did not reduce contractile activity, but in fact, if anything, it increased the speed of contraction

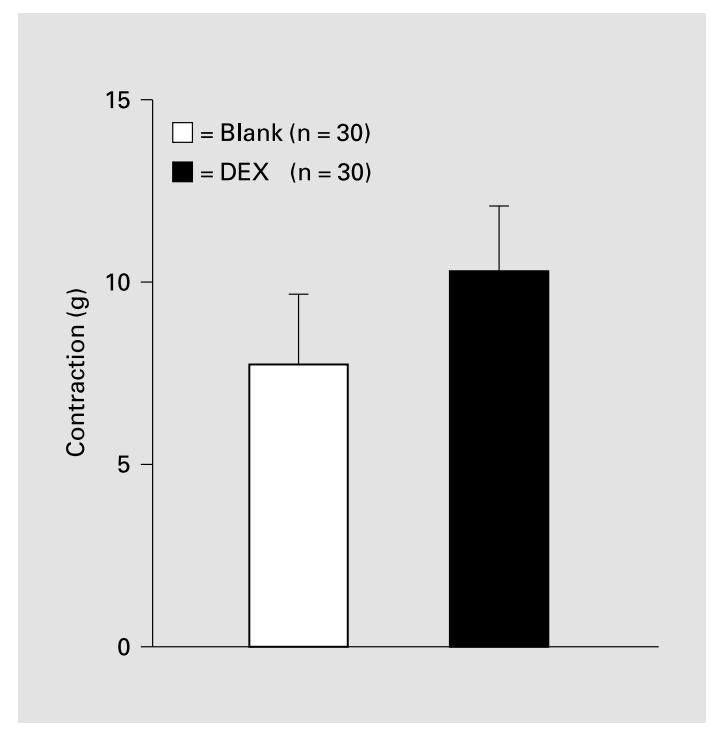

Fig. 2. Figure showing the contractile effect of the sheep duodenal extract incubated with or without erythromycin $\left(\mathrm{DEX}, 10^{-5} \mathrm{M}\right)$. Figures represent mean \pm SE of 30 experiments.

3-5 times (fig. 3 ) as the peak contraction was reached in 5-10 min.

\section{Extractions}

Extractions of the blank and DEX from the duodenal extract were performed with three organic solvents of different lipophilicity and polarity: diethyl ether, chloroform and ethyl acetate. When the reconstituted aliquots of these extracts (in Krebs' solution) were added to the organ bath and tested for contractile activity of gallbladder strips no activity was detected.

\section{Discussion}

The mechanism of the prokinetic effect of erythromycin on the gallbladder has not been clarified. Previous in vivo studies in man and experimental animals clearly showed that ad- 
Fig. 3. The effect of heat treatment on the contractile activity of the duodenal extract (DEX). The first part of tracing represents contractile response to the extract (not heated) while the second part represents contractile response to the boiled extract.

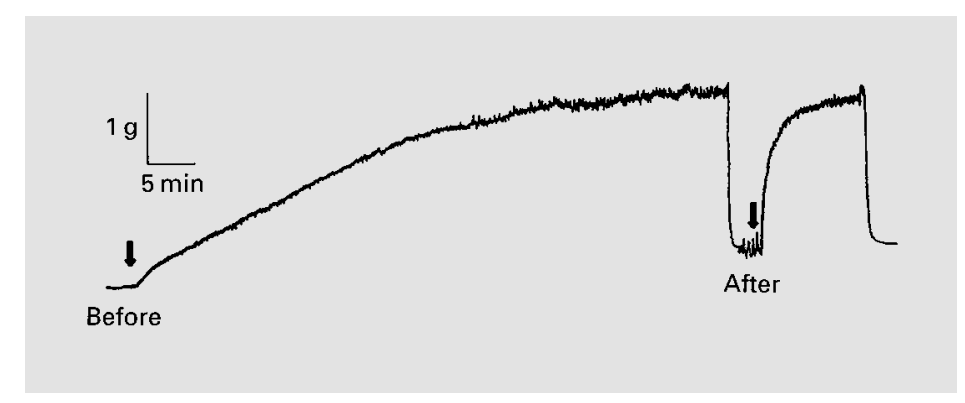

ministration of erythromycin enhanced migrating motor complexes of the gut [6] and induced gallbladder contractions accompanied by increased motilin blood levels. However, as shown in this study and by others [3], isolated gallbladder strips from several species failed to respond to motilin and erythromycin. It is therefore quite possible that the prokinetic action of erythromycin, in vivo, could be mediated by a neural mechanism of the enteric nervous plexus, particularly in view of the fact that the in vivo response was blocked by atropine, somatostin and a $5-\mathrm{HT}_{3}-$ receptor blocker [7, 8].

The question of a local neural involvementin the release process of a duodenal prokinetic factor has been further illustrated in patients with truncal vagotomy or antrectomy and Billroth II anastomosis. In this study it was shown that the long vagus nerve was not essential for erythromycin-induced effects on the gallbladder, although duodeno-jejunal anatomical integrity was reported as a precondition [9]. Hence it is obvious that the motility-stimulating effect emanates from the gut, mediated either by a neurogenic mechanism or a duodenal prokinetic factor. Contractionstimulating properties of erythromycin have so far only been shown to occur in duodenal, gastric and colonic smooth muscle preparation $[5,10,11]$ and myoelectric activity in the antrum and duodenum of sheep [12].
In our study we could show that CCK did not appear to be the duodenal prokinetic factor since gallbladder contraction induced by DEX was not blocked by lorglumide, a specific CCK blocker. This is also supported by an in vivo study in which erythromycininduced gallbladder contractions were not accompanied by increased plasma levels of CCK and lorglumide did not prevent gallbladder contraction $[13,14]$. Another polypeptide, gastrin, did not induce a contraction in our experiments with gallbladder strips and therefore cannot be implicated. Histamine $\left(10^{-6}\right.$ $M)$ elicited forceful contraction of sheep gallbladder strips but the histamine-1 antagonist chlorpheniramine did not block the contractions elicited by the blank and DEX, indicating that the contractions were not mediated via activation of histamine receptors.

Evidence from clinical studies seems to indicate that cholinergic mechanisms either control the release of a motility-inducing factor or mediate contraction in the gallbladder since the contractions were blocked by atropine [14-16]. In our in vitro experiments we noted only a small reduction of the blank and DEX-induced contraction after addition of atropine $(<20 \%)$, indicating only a partial involvement of the cholinergic system in this response. It is possible that the cholinergic system might be involved in the contractile mechanism: atropine, added to the bath dur- 
ing the peak response to the duodenal extract, reduced the contractile response. We also tested the possible $5-\mathrm{HT}_{3}$ blocking effect of tropisetron during the tissue incubation and on top of the contractile response of the gallbladder strips, but without effect. Failure of nordihydroguaiaretic acid to affect the response would suggest that the prokinetic factor is unlikely to be a leukotriene.

An attempt was made to identify possible active constituents present in the extracts. This we did by extracting with three organic solvents followed by evaporation to dryness, reconstitution in physiological solution and testing on gallbladder strips. The results showed that the prokinetic factor was not extracted by any of these solvents, since no contraction was seen following extraction with any of these solvents. In order to narrow down the possible active compound of the duodenal prokinetic factor, we also used biological screening. The rat stomach strip responded with a contraction to blank and DEX, but the guinea-pig ileum, rat aorta, sheep trachea were not responsive.

The present study presents evidence for the presence of a water-soluble, humoral duodenal prokinetic factor stimulating gallbladder smooth muscle contraction. At the present time we can only speculate about the chemical structure of the compound(s). Heat stability rules out proteins although it could be a polypeptide. The fact that the onset of contraction improved following heat treatment could suggest that the extract contained more than one kinetic factor. One factor, which was heatlabile, delayed the onset of contractile response.

In this exploratory study the chemical characterization of the active principle of the duodenal prokinetic factor was limited to screening procedures of lipid solubility, thermal sensitivity and pharmacological blocking experiments. Further studies will include dial- ysis, column chromatography and LC/MS. The mass-fragmentation patterns, which could be considered as fingerprints of any of the compounds separated, may serve as a good reference for future identification and confirmation of these compounds when separated by other techniques.

\section{Conclusion}

It was concluded that a heat-stable prokinetic factor was released from the sheep duodenum. This factor produced reproducible contractions of gallbladder strips that did not involve muscarinic, histaminergic or serotonergic receptors. It is also not a metabolite of arachidonic acid metabolism. Further studies are required to identify and characterize this factor.

\section{Acknowledgement}

This work was supported by grants MR 034 from Kuwait University (O.T.) and KFAS 97-07-01 (M.A.O.). 


\section{References}

1 Shaffer EA: Abnormalities in gallbladder function in cholesterol gallstone disease: Bile and blood, mucosa and muscle - the list lengthens. Gastroenterology 1992;102:18081812.

2 Tierney S, Pitt HA, Lillemoe KD: Physiology and pathophysiology of gallbladder motility. Surg Clin North Am 1993;73:1267-1290.

3 Davison JS: Physiology of extraheb transport; in Bouchier IAD, Allen RN, Hodgson HJF, Keighley MRB (eds): Gastroenterology. London, Saunders, 1993, pp 1688-1692.

4 Peeters TL: Erythromycin and other macrolides as prokinetic agents. Gastroenterology 1993;105:18861899.

5 Parkman HP, Pagano AP, Vozell MA, Ryan JP: Gastrokinetic effects of erythromycin: Myogenic and neurogenic mechanisms in rabbit stomach. Am J Physiol 1995;269:G418G428.

6 Costa A, De Ponti F, Gibelli G, Crema F, d'Angelo L: In vivo characterization of the colonic prokinetic effect of erythromycin in the rabbit. Pharmacology 1997;54:64-75.
7 Fiorucci S, Bosso R, Morelli A: Erythromycin stimulates gallbladder emptying and motilin release by atropine sensitive pathways. Gastroenterology 1991;100:A740.

8 Mizumoto A, Ohtawa M, Ueki T, Segikuchi S: Motilide: (EM523) mimics motilin in interdigestive gallbladder contraction in the dog. Gastroenterology 1991;100:A740.

9 Masclee AA, Ledeboer ML, Gielkens HG, van der Kleij FG, Jebbink MC, Lamers CB: The effect of erythromycin on gallbladder emptying in patients with antrectomy or truncal vagotomy. Am J Gastroenterol 1995;100:A320.

10 Depoortere I, Peters TL, Matthijs G Cachet T, Hoogmartens J, Vantrappen G: Structure-activity relation of erythromycin-related macrolides in inducing contractions and in displacing bound motilin in rabbit duodenum. J Gastrointest Motil 1989;1: 150-159.

11 Hasler WL, Heldsinger A, Owyang C: Erythromycin contracts rabbit colon myocytes via occupation of motilin receptors. Am J Physiol 1992;262:G50-G55.
12 Plaza MA, Arruebo MP, Murillo MD: Effect of motilin, somatostatin and bombesin on gastroduodenal myoelectric activity in sheep. Life Sci 1996;58:1413-1423.

13 Jebbink MCW, Masclee AAM, van der Kleij FGH, Schipper J, Rovati LC, Lamers CB: Effect of loxiglumide (CR-1505) and atropine on erythromycin induced gallbladder contraction in man. Gastroenterology 1991;100:A320.

14 Jebbink MCW, Masclee AAM, van der Kleij FGH, Schipper J, Rovati LC, Jansen JB, Lamers CB: Effect of loxiglumide and atropine on erythromycin-induced reduction in gallbladder volume in human subject. Hepatology 1992;16:937-942.

15 Fiorucci S, Bosso R, Morelli A: Erythromycin stimulates gallbladder emptying and motilin release by atropine sensitive pathways. Dig Dis Sci 1992;37:1678-1674.

16 Fiorucci S, Santucci L, Morelli A: 5 Hydroxytryptamine-3-receptor antagonist modulates gallbladder emptying and motilin release induced by erythromycin. Dig Dis Sci 1993;38:2236-2240. 